\title{
Increasing Trends in Deep Infiltrating Endometriosis (DIE) with Bilateral Endometrioma from Adolescence till Menopause
}

\author{
Ruby Bhatia ${ }^{1}$, Sunita Mor $^{2}$, Tanushree Pandey ${ }^{3}$, Naazbir Kaur ${ }^{4}$
}

${ }^{1}$ Department of Obstetrics and Gynaecology, MMIMSR, Mullana, Ambala, Haryana, India. ${ }^{2}$ Department of Obstetrics and Gynaecology, MMIMSR, Mullana, Ambala, Haryana, India. ${ }^{3}$ Department of Obstetrics and Gynaecology, MMIMSR, Mullana, Ambala, Haryana, India. ${ }^{4}$ Department of Obstetrics and Gynaecology, MMIMSR, Mullana, Ambala, Haryana, India.

\section{INTRODUCTION}

Endometriosis is a clinical and a pathological entity characterised by the presence of tissue resembling functional endometrial gland and stroma outside the uterine cavity. Endometriosis most commonly affects women in the age group of 24-35 yrs. ${ }^{1}$ Postmenopausal endometriosis accounts for less than $3 \%$ of the cases. ${ }^{2}$ The common clinical presentation in a case of endometriosis include chronic pelvic pain, dysmenorrhoea, infertility, dyschezia, dyspareunia and adnexal mass. Diagnosis is usually suspected on basis of signs and symptoms and confirmed on imaging. Transvaginal ultrasound and MRI (especially in DIE) remains not only a diagnostic modality but also the best guide to decide the management. ${ }^{3}$ Many a times, gravity of symptoms may not correlate with severity of disease and patient may remain asymptomatic even with severest form of disease. Many a years may be lost before the definitive diagnosis and management of endometriosis is established.

Factors associated with an increased risk of endometriosis include family history, nulliparity, early menarche, late menopause, short menstrual cycles, obstruction of menstrual outflow (Mullerian anomalies), exposure to diethylstilboestrol in utero, lower body mass index, alcohol use, exposure to severe physical or sexual abuse in childhood and a higher consumption of trans unsaturated fat. ${ }^{4}$ DIE (deep infiltrating endometriosis) is a severe form of stage 4 endometriosis that extends $>5 \mathrm{~mm}$ under the peritoneal surface. In other words, endometriosis found in a location other than the superficial tissues infiltrating uterosacral ligaments, rectovaginal septum, parametrium, bowel, pelvic wall or urinary bladder constitutes DIE 5. In my last 30 years of clinical experience, increasing trends of DIE with bilateral endometriomas has been observed. Here, we describe cases with severe endometriosis and bilateral endometriomas from adolescence till menopause. Deep infiltrating endometriosis has varying clinical presentations with certain diagnostic signs and symptoms. Bilateral endometriomas along with DIE has been observed in all the age groups in this series, especially being diagnosed at more than 35 years of age.
Corresponding Author: Dr. Tanushree Pandey, II-Block, MMIMSR, Mullana, Ambala, Haryana, India.

E-mail: pandeytanushree10@gmail.com

DOI: $10.14260 /$ jemds/2020/128

Financial or Other Competing Interests: None.

How to Cite This Article:

Bhatia R, Mor S, Pandey T, et al. Increasing trends in deep infiltrating endometriosis (DIE) with bilateral endometrioma from adolescence till menopause. J. Evolution Med. Dent. Sci. 2020;9(08):576-581, DOI: $10.14260 /$ jemds/2020/128

Submission 28-11-2019, Peer Review 30-01-2020 Acceptance 05-02-2020, Published 24-02-2020. 


\section{Case 1}

A 47 year old multiparous postmenopausal woman presented with a 22 weeks sized mass in the abdomino-pelvic region associated with pain and heaviness in the lower abdomen since many years. There was history of congestive dysmenorrhea in her menstrual period since last many years, which was not relieved by NSAIDs. Instead, injectable painkillers were required in every menstrual cycle for relief of dysmenorrhea. Associated history of dyspareunia and dyschezia for last many years was suggestive of endometriosis in this case. On examination, there was an abdomino-pelvic mass, 22 weeks in size. The mass was soft to firm in consistency, tender with smooth surface and restricted mobility. On per speculum examination cervix was found to be normal and deviated to right side. PAP smear was negative for any intraepithelial lesion. On Bimanual pelvic examination- a mass of about 20 weeks size, soft to firm in consistency with smooth surface was felt. Uterus could not be defined separately from the mass. Mobility was restricted and the mass was tender on movement. Movement of the mass was transmitted to the Cervix and vice versa. Bilateral fornices were full and tender.

Laboratory investigations were as followingHaemoglobin- 11.2 gm\%, TLC: 6,600/ $\mathrm{mm}^{3}$, Blood urea: 16 $\mathrm{mg} / \mathrm{dl}$, Serum creatinine: $0.6 \mathrm{mg} / \mathrm{dl}$, Total Bilirubin: $0.3 \mathrm{mg} / \mathrm{dl}$, Urine Microscopy: Normal, Serum TSH: $1.1 \mu \mathrm{Iu} / \mathrm{ml}$. Ca-125: Raised (239.6 U/L), Serum Prolactin: $9.11 \mathrm{ng} / \mathrm{dl}$ and Serum FSH: $30 \mathrm{U} / \mathrm{L}$. ESR: $56 \mathrm{~mm}$ in the $1^{\text {st }}$ hour, Mantoux: negative, Sputum for Acid Fast Bacilli: negative, Chest X-ray: Normal.

Ultrasound findings showed features of haematometra/ pyometra with Bilateral haematosalpinx/pyosalpinx with a uterine size of $17 \times 6.3 \mathrm{cms}$ and ET of $4 \mathrm{~mm}$. MRI findings were also similar showing and enlarged uterus of $17 \times 8 \times 6 \mathrm{~cm}$ size with organized haemorrhagic endometrial collection of $15 \times 6$ $\mathrm{x} 7 \mathrm{~cm}$ in size extending into upper cervical canalhaematometra. Bilateral adnexa showed complex tuboovarian cystic lesions with chronic blood products with right ovary measuring $10 \times 3 \mathrm{~cm}$ in size and left measuring $7 \times 2 \mathrm{~cm}$ in size- bilateral endometriomas.

A provisional diagnosis of haematometra with haematosalpinx with bilateral endometrioma? Pyometra with pyosalpinx with bilateral endometrioma was made. Vaginal dilation under anaesthesia was done- No blood or pus came out. Fractional curettage showed keratinous and degenerated material along with few inflammatory cells and areas of haemorrhage. Endometrium was negative for Acid Fast Bacilli and CBNAAT, ruling out genital tuberculosis.

An exploratory laparotomy was done after informed consent under general anaesthesia, preceded by ureteric DJ Stenting so to avoid ureteric injury, in view of large haematometra with bilateral endometrioma and haematosalpinx. The peritoneum was tacked to underlying structures with dense adhesions between uterus, adnexa, gut and omentum. Adhesiolysis was done. The uterus was uniformly enlarged up to 20 weeks size with soft to firm consistency with Right Haematosalpinx of $14 \times 5 \mathrm{~cm}$ size and a Left Haematosalpinx of $7 \times 5 \mathrm{cms}$, and bilateral endometriomas ( $6 \times 5 \mathrm{~cm}$ and $5 \times 2 \mathrm{~cm}$ ) in size. The pouch of Douglas was obliterated by DIE with dense fibrosis and with puckering of the uterosacral ligaments. Subtotal hysterectomy with bilateral salpingo-oophorectomy was done. All adhesions and endometriotic implants were ablated and excised. The ureters on both sides were found very near to the lateral lower surface of the cervix. Decision to proceed with a subtotal hysterectomy was taken so as to avoid injury to ureter and a difficult dissection through the puckered uterosacral ligaments to reach below the cervix. On cut section, about 1500 cc of haematometra oozed out. Hence, a differential diagnosis of DIE with endometriomas should always be kept in mind in case of a postmenopausal woman.

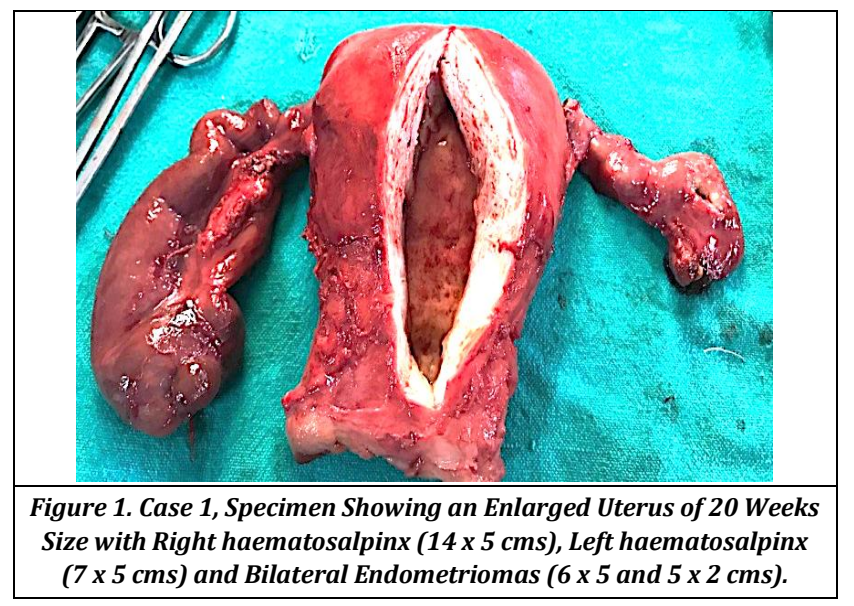

Case 2

A similar case of DIE with bilateral endometriomas has been reported by us in a 45 year old woman who presented with acute abdominal pain with haemoperitoneum in shock in the emergency department. The ultrasound showed a large $20 \mathrm{x}$ $10 \mathrm{~cm}$ cystic mass in left adnexa with uterine size $14 \mathrm{~cm}$ with multiple fibroids with fluid in peritoneal cavity and cul-de-sac. On exploratory laparotomy, a right endometrioma (10 x 8 $\mathrm{cms}$ ) with rupture of capsule leading to haemoperitoneum of about three litres was seen. Bilateral haematosalpinx was seen along with $8 \times 5 \mathrm{~cm}$ size endometrioma on the left side. Uterus was 10 weeks size along with haematometra. Dense adhesions were present between the endometriomas, uterus, gut and omentum. Total abdominal hysterectomy with bilateral salpingo-oophorectomy was done. ${ }^{6}$

\section{Case 3}

38 year old $\mathrm{P}_{2} \mathrm{~L}_{2}$ with previous two caesarean sections presented with chronic pelvic pain, dyspareunia, dyschezia and polymenorrhagia. Her CA-125 was raised (320 U/L). Ultrasound showed evidence of endometrioma of size 6.7 x 5.9 cms on right side. MRI showed shows a focal well defined cystic lesion arising from right ovary appearing hyperintense on both $\mathrm{T}_{1} \& \mathrm{~T}_{2}$ weighted sequence, not suppressed on fat saturated images suggestive of haemorrhagic content. The lesion showed fluid levels with $\mathrm{T}_{2}$ shading effect suggesting endometrioma. Left ovary and uterus were normal. On pelvic examination uterus was retroverted, fixed with tenderness and fullness in right adnexa. Suspecting torsion, an exploratory laparotomy was planned. Dense adhesions with gut, omentum and endometrioma on right side were excised. Excision and ablation of the endometrioma and all the implants was done. There were extensive peri tubal and periovarian adhesions also. Post surgery, patient was advised continuous OCPs, but she opted for cyclical OCPs and was lost to follow up. One year later, the patient presented to OPD with chronic pelvic pain. USG showed bilateral endometriomas of size $8 \times 8$ and $10 \times 8 \mathrm{cms}$. Patient was put on continuous OCPs. 
To our surprise, MRI after one year showed complete regression of endometriomas and endometriotic implants and the patient is still continuing with combined OCPs.

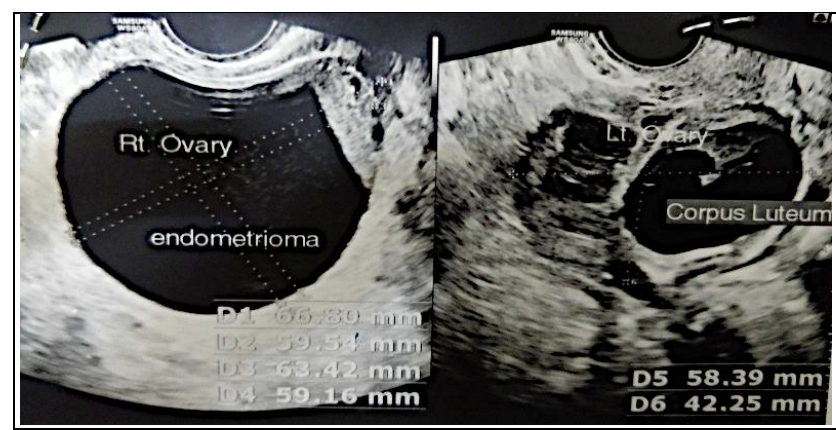

Figure 2. Case 3, Right Ovary Shows a Well-Defined Cystic Mass Measuring 6.3 x $5.9 \mathrm{~cm}$ Containing Homogenously Low Level Internal Echoes and Fluid-Fluid Level-Chocolate Cyst. Left Ovary Measures 5.8 $x 4.2 \mathrm{~cm}$. Two Well Defined Cystic Masses Measuring 4 x $2.7 \mathrm{~cm}$ and $2.4 \times 2 \mathrm{~cm}$ Containing Internal Echoes in them are seen-? Corpus Luteal Cyst.

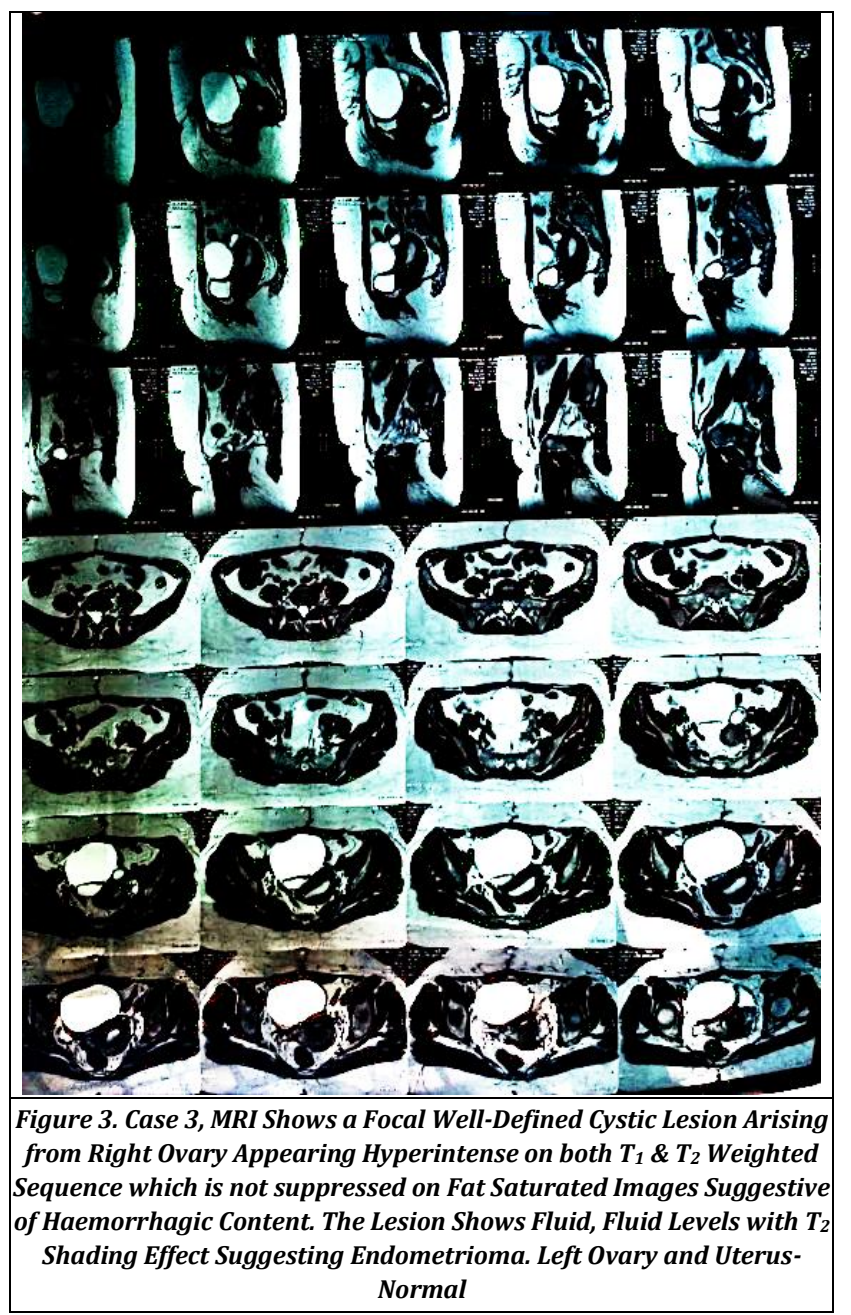

Case 4

A 37 year old woman $\mathrm{P}_{2} \mathrm{~L}_{2}$ presented to OPD with complain of pain lower abdomen and dyspareunia since last six months. On examination she had a abdominopelvic mass 16 weeks in size. Per speculum examination showed a healthy cervix and vagina. On per vaginum examination, uterus was 16 weeks size. A $6 \times 6 \mathrm{cms}$ mass in right fornix felt, not separate from uterus and a $5 \times 6 \mathrm{cms}$ mass felt in the left fornix. Ultrasonography showed multiple fibroids in the uterus with the largest measuring $5.6 \times 5 \mathrm{cms}$ in posterior wall. ET-5 mm Both ovaries showed cystic lesions with internal echoes, measuring $5.7 \times 4.4 \mathrm{cms}$ in right ovary and $5.3 \times 5.2 \mathrm{cms}$ in left ovary, suggestive of bilateral endometriomas. A tubular cystic structure with internal echoes seen adjacent to left ovary, suggestive of left haematosalpinx. Her MRI depicted a similar picture of Multiple uterine fibroid with bilateral complex tuboovarian masses with internal echoes- endometriomas and left haematosalpinx. On exploratory laparotomy, POD was obliterated with adhesions. Bilateral endometrioma with left haematosalpinx was seen. Total abdominal hysterectomy with bilateral salpingo-oophorectomy was done.

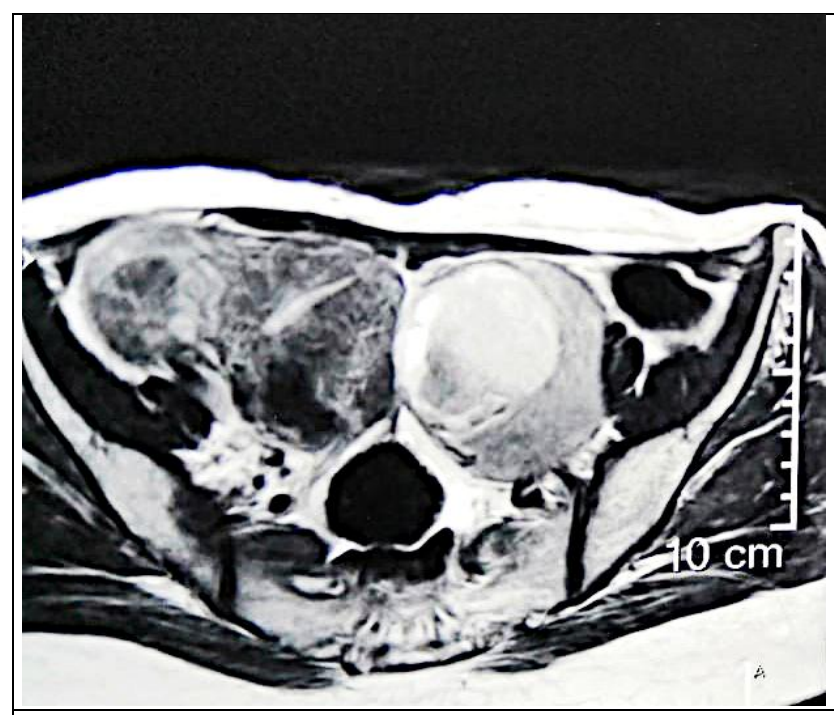

Figure 4. Case 4, MRI- Uterus is Bulky, Measures 12 × 6.5 × 5.7 cms. A Large Subserosal Fibroid Measuring $5.5 \times 4.9 \mathrm{cms}$ is seen in Fundal Region. Multiple Smaller Intramural and Subserosal Fibroids are seen in Body Region in Anterior and Posterior Wall Largest Measuring $3 x$ 2.2 cms in Posterior Wall. Complex Tubo-Ovarian Cystic Lesion are Seen in Bilateral Adnexa Measuring Approximately $4.8 \times 3.7 \mathrm{cms}$ on Right Side and $7.2 \times 6 \mathrm{cms}$ on Left Side. Dilated Fallopian Tubes are seen at Medial Aspect of Lesions (Left>Right). Multiple Thin Septations are seen within them. Chronic Blood Products Appearing Heterogeneously Hyperintense on $T_{1}$ and $T_{2}$ and FAT SAT with Shedding Effect on $T_{2} W_{1}$. Bilateral Ovaries are not Separately Visualized

Case 5

31 year old woman with primary infertility for last 10 years presented with heaviness in lower abdomen and menorrhagia A bimanual pelvic examination confirmed large bilateral adnexal masses. Ultrasound and MRI confirmed nulliparous uterus with $16 \times 10 \mathrm{~cm}$ right adnexal mass and $15 \times 10 \mathrm{~cm}$ left ovarian mass with diffused internal echoes. CA-125 was raised (46 IU/L). Complete workup for infertility and tumour markers were normal except for endometriosis. On exploratory laparotomy, DIE with dense adhesions between gut, omentum and uterus were seen. Bilateral large endometriomas in both ovaries with altered tarry chocolate material was seen. Conservative surgery with resection of bilateral endometriomas and endometrial implants with adhesiolysis was done. Patient was put on injection GnRh agonists (Injection Leuprolide $3.75 \mathrm{mg}$ intramuscular) monthly for three months and was advised IVF. 6

Case 6

31 year old presented with primary infertility for 10 years. She had complaints of congestive dysmenorrhea, dyspareunia and 
heaviness in lower abdomen. On bimanual pelvic examination, there was bilateral tender, soft to firm adnexal mass of size 10 x $7 \mathrm{cms}$ and $10 \times 8 \mathrm{cms}$ in right and left adnexa, respectively. All investigations were within normal limits except for CA-125 which was raised (75 IU/L). CT whole abdomen and pelvis revealed $7.3 \times 4.9 \mathrm{~cm}$ lesion with internal echoes in right adnexa. A 4.9 × $3.5 \mathrm{~cm}$ enlarged left ovary with well-defined 6.2 x $2.7 \mathrm{cms}$ tubular structure adjacent to left ovary suggestive of haematosalpinx. Genital tuberculosis was ruled out. Exploratory laparotomy confirmed DIE with bilateral fetal head size endometriomas with large haematosalpinx in left adnexa. Resection of endometriomas with fulguration and ablation of endometriotic implants was done. Post-operative $\mathrm{GnRh}$ agonist was given and was advised IVF6.

\section{Case 7}

An unmarried 19 year old adolescent girl presented in gynaecology out-patient department with 18 weeks size abdomino-pelvic mass and subacute pain and depression. She was poorly built, undernourished, school drop-out from rural background and lower socio-economic status. Patient was anaemic, haemodynamically stable. $\mathrm{CBC}$, Thyroid profile, X-ray chest, Mantoux and ESR were normal. CA-125 was marginally raised (60IU/L). However, serum beta-hCG and serum alphafetoprotein were normal. CT abdomen and pelvis depicted 9x7 $\mathrm{cm}$ smooth walled, well defined right adnexal mass displacing adjacent gut loops and iliac vessels. Left adnexa showed 7.5x5.3 adnexal mass. A provisional diagnosis of bilateral endometrioma? bilateral tubo-ovarian mass was made. Exploratory laparotomy was planned after informed consent. Bilateral $10 \times 10 \mathrm{cms}$ endometriomas replacing both ovaries, filled with altered tarry chocolate material, densely adherent with uterus, gut and omentum was found. Uterus was 10 weeks size with large bilateral haematosalpinx. Dense adhesions in pelvis with bowel and bladder, uterosacral ligaments with fibrous bands and obliteration of pouch of Douglas was seen. Thus, a catastrophic picture of DIE with bilateral endometriomas, haematosalpinx and large uterus was established. Bilateral excision of endometriomas with endometriotic implants was done. Patient was put on continuous combined oral contraceptive pills, three weeks after the surgery. Patient is fine and has been advised for IVF after marriage. ${ }^{7}$

\section{Case 8}

24 year old unmarried girl presented with severe congestive dysmenorrhea for last three years. Her pain was not relieved even by injectable painkillers, leading to work absenteeism. Ultrasound and MRI pelvis showed nulliparous uterus with bilateral endometriomas ( $5.2 \times 4.7 \mathrm{cms}$ in left adnexa and a 2.5 $x 1.9 \mathrm{cms}$ cystic lesion with internal echoes in right adnexa). A tubular multiseptated structure $7 \times 2.5 \mathrm{cms}$ was seen adjacent to right ovary? haematosalpinx. CA-125 was minimally raised (62 IU/L). After complete work up, operative laparoscopy and histopathology confirmed DIE with bilateral large endometriomas and left haematosalpinx. Excision of endometriomas, adhesiolysis with ablation of endometriotic implants was done. Post-operatively patient was on continuous combined oral contraceptive pills. ${ }^{6}$

\section{Case 9}

26 year old, unmarried, post-graduate doctor had complaints of congestive dysmenorrhea for last many years. Her USG and MRI showed bilateral endometriomas $(6 \times 6$ and $5 \times 6 \mathrm{cms}$ in size). The patient opted for medical management with continuous OCPs. After three years of use, both endometriomas have reduced in size.

\begin{tabular}{|c|c|c|c|c|c|c|c|}
\hline$\frac{0}{2}$ & & 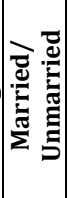 & 苋 & 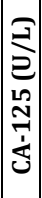 & 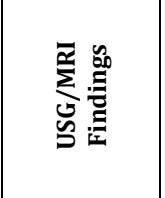 & 总营 & 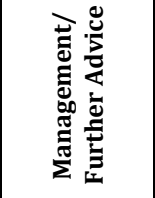 \\
\hline 1. & 安 & $\sum_{\substack{\pi \\
\frac{\pi}{\pi}}}$ & \begin{tabular}{|} 
Congestive \\
dysmenorrhea, \\
chronic pelvic \\
pain, \\
abdominopelvic \\
mass
\end{tabular} & $\begin{array}{c}23 \\
9\end{array}$ & $\begin{array}{c}\text { Hematometra } \\
\text { with bilateral } \\
\text { endometrioma } \\
\text { with bilateral } \\
\text { haematosalpinx } \\
\text { with enlarged } \\
\text { uterus. }\end{array}$ & \begin{tabular}{|c|} 
Dense adhesions \\
between adnexa, \\
uterus, gut and \\
omentum. uterus \\
20 weeks in size. \\
Bilateral \\
endometrioma (6 \\
x 5 and 5 x $2 \mathrm{cms}$ ) \\
with bilateral \\
haematosalpinx.
\end{tabular} & $\begin{array}{l}\text { TAH with } \\
\text { BSO }\end{array}$ \\
\hline 2. & 농 & $\stackrel{\frac{\sigma}{\pi}}{\overbrace{\pi}^{\pi}}$ & $\begin{array}{c}\text { Acute abdomen } \\
\text { with shock }\end{array}$ & - & $\begin{array}{c}\text { Cystic mass in } \\
\text { left adnexa } 20 \mathrm{x} \\
10 \mathrm{cms} . \\
\text { Multiple } \\
\text { uterine fibroids } \\
\text { with fluid in } \\
\text { cul-de-sac }\end{array}$ & \begin{tabular}{|c|} 
Right \\
endometrioma \\
$(10 \times 8 \mathrm{cms})$ with \\
rupture of \\
capsule. \\
haemoperitoneu \\
m of three litres. \\
Bilateral \\
haematosalpinx \\
along with $8 \times 5$ \\
cm size \\
endometrioma on \\
left side. Uterus \\
10 weeks size \\
along with \\
haematometra. \\
Dense adhesions \\
between the \\
endometriomas, \\
uterus, gut and \\
omentum. \\
\end{tabular} & $\begin{array}{l}\text { TAH with } \\
\text { BSO }\end{array}$ \\
\hline 3. & $\mid \begin{array}{l}\infty \\
m\end{array}$ & 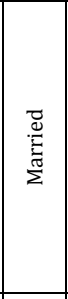 & $\begin{array}{c}\text { Chronic pelvic } \\
\text { pain, } \\
\text { dyspareunia, } \\
\text { dyschezia and } \\
\text { polymenorrhagi } \\
\text { a }\end{array}$ & $\begin{array}{c}32 \\
0\end{array}$ & \begin{tabular}{|c|} 
Endometrioma \\
$-7 \times 5.9 \mathrm{cms}$ on \\
right side. Left \\
ovary and \\
uterus normal. \\
After 1 -year \\
USG showed \\
bilateral \\
endometriomas \\
of size $8 \times 8$ and \\
$10 \times 8 \mathrm{cms}$. \\
\end{tabular} & $\begin{array}{c}\text { Dense adhesions } \\
\text { with gut, } \\
\text { omentum and } \\
\text { endometrioma on } \\
\text { right side }\end{array}$ & $\begin{array}{c}\text { Excision and } \\
\text { ablation of all } \\
\text { implants. OCPs }\end{array}$ \\
\hline 4. & $\hat{m}$ & $\frac{\bar{d}}{\overbrace{\pi}^{\pi}}$ & $\begin{array}{c}\text { Pain lower } \\
\text { abdomen, } \\
\text { dyspareunia, } \\
\text { and } \\
\text { abdominopelvic } \\
\text { mass. }\end{array}$ & 45 & \begin{tabular}{|c|} 
Multiple \\
fibroids. \\
Bilateral \\
endometrioma \\
(5.7 x $4.4 \mathrm{cms}$ \\
in right and 5.3 \\
x $5.2 \mathrm{cms}$ in left \\
ovary), with left \\
haematosalpinx \\
. \\
\end{tabular} & \begin{tabular}{|c|} 
POD obliterated \\
with adhesions \\
with bilateral \\
endometrioma \\
and left \\
haematosalpinx.
\end{tabular} & TAH WITH BSO \\
\hline 5. & $\bar{m}$ & 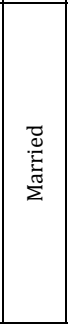 & \begin{tabular}{|c|} 
Primary \\
infertility, \\
Heaviness in \\
lower abdomen, \\
menorrhagia
\end{tabular} & 46 & \begin{tabular}{|} 
Nulliparous \\
uterus with \\
$16 \times 10 \mathrm{~cm}$ right \\
adnexal mass \\
and $15 \times 10 \mathrm{~cm}$ \\
left ovarian \\
mass with \\
diffused \\
internal echoes.
\end{tabular} & \begin{tabular}{|c|} 
DIE with dense \\
adhesions \\
between gut, \\
omentum and \\
uterus. Bilateral \\
large \\
endometriomas.
\end{tabular} & \begin{tabular}{|c|} 
Conservative \\
surgery with \\
resection of \\
bilateral \\
endometrioma \\
s and \\
endometrial \\
implants with \\
adhesiolysis. \\
GnRH agonists \\
and advised \\
IVF \\
\end{tabular} \\
\hline
\end{tabular}




\begin{tabular}{|c|c|c|c|c|c|c|}
\hline 6. $31 \mid$ & 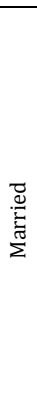 & $\begin{array}{c}\text { Primary } \\
\text { infertility, } \\
\text { congestive } \\
\text { dysmenorrhea, } \\
\text { dyspareunia and } \\
\text { heaviness in } \\
\text { lower abdomen. }\end{array}$ & $\begin{array}{c}12 \\
5\end{array}$ & $\begin{array}{c}7.3 \times 4.9 \mathrm{~cm} \\
\text { lesion with } \\
\text { internal echoes } \\
\text { in right adnexa. } \\
\text { A } 4.9 \times 3.5 \mathrm{~cm} \\
\text { enlarged left } \\
\text { ovary with } \\
\text { well-defined } 6.2 \\
\text { x } 2.7 \mathrm{cms} \\
\text { tubular } \\
\text { structure } \\
\text { adjacent to left } \\
\text { ovary } \\
\text { suggestive of } \\
\text { haematosalpinx }\end{array}$ & $\begin{array}{c}\text { DIE with bilateral } \\
\text { fetal head size } \\
\text { endometriomas } \\
\text { with large } \\
\text { haematosalpinx } \\
\text { in left adnexa. }\end{array}$ & $\begin{array}{c}\text { Resection of } \\
\text { endometrioma } \\
\text { s with } \\
\text { fulguration and } \\
\text { ablation of } \\
\text { endometriotic } \\
\text { implants. GnRH } \\
\text { agonist and } \\
\text { advised IVF. }\end{array}$ \\
\hline 7. 19 & 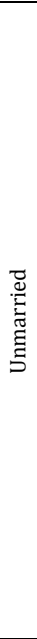 & $\begin{array}{c}\text { Abdomino- } \\
\text { pelvic mass, } \\
\text { subacute pain } \\
\text { and depression. }\end{array}$ & 60 & $\begin{array}{c}9 \times 7 \mathrm{~cm} \text { right } \\
\text { adnexal mass } \\
\text { displacing } \\
\text { adjacent gut } \\
\text { loops and iliac } \\
\text { vessels. Left } \\
\text { adnexa showed } \\
7.5 \times 5.3 \\
\text { adnexal mass. }\end{array}$ & \begin{tabular}{|c|} 
Bilateral $10 \times 10$ \\
cms \\
endometriomas \\
replacing both \\
ovaries, filled \\
with altered tarry \\
chocolate \\
material, densely \\
adherent with \\
uterus, gut and \\
omentum. Uterus \\
was 10 weeks size \\
with large \\
bilateral \\
haematosalpinx. \\
Dense adhesions \\
in pelvis with \\
bowel and \\
bladder, \\
uterosacral \\
ligaments with \\
fibrous bands and \\
obliteration of \\
pouch of Douglas.
\end{tabular} & \begin{tabular}{|c} 
Bilateral \\
excision of \\
endometrioma \\
s along with \\
implants. \\
Continuous \\
combined oral \\
contraceptive \\
pills. Advised \\
IVF after \\
marriage.
\end{tabular} \\
\hline 8. 24 & 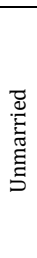 & $\begin{array}{c}\text { congestive } \\
\text { dysmenorrhea }\end{array}$ & 62 & $\begin{array}{c}\text { Bilateral } \\
\text { endometriomas } \\
(5.2 \times 4.7 \mathrm{cms} \\
\text { in left adnexa } \\
\text { and a } 2.5 \times 1.9 \\
\text { cms in right } \\
\text { adnexa with } 7 \times \\
2.5 \mathrm{cms} \text { ? right } \\
\text { haematosalpinx }\end{array}$ & $\begin{array}{c}\text { Excision of } \\
\text { endometriomas, } \\
\text { adhesiolysis with } \\
\text { ablation of } \\
\text { endometriotic } \\
\text { implants. }\end{array}$ & $\begin{array}{c}\text { Continuous } \\
\text { combined oral } \\
\text { contraceptive } \\
\text { pills }\end{array}$ \\
\hline 9. 26 & 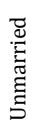 & $\begin{array}{c}\text { Congestive } \\
\text { dysmenorrhea }\end{array}$ & 48 & $\begin{array}{c}\text { Bilateral } \\
\text { endometriomas } \\
(6 \times 6 \text { and } 5 \times 6 \\
\text { cms in size }) .\end{array}$ & - & $\begin{array}{l}\text { Continuous } \\
\text { OCPs. }\end{array}$ \\
\hline \multicolumn{7}{|c|}{ Table 1. Details of Individual Cases } \\
\hline
\end{tabular}

\section{DISCUSSION}

Endometriosis is a disease of the reproductive age group, rarely seen before menarche or after menopause. ${ }^{8}$ Diagnosis of endometriosis in adolescents and menopausal age group still remains a challenge. $69.6 \%$ of young adolescent girls with chronic pelvic pain are found to have endometriotic implants on laparoscopy. ${ }^{9} 19$ year old young adolescent girl in our study had bilateral endometriomas with DIE while 21 year old unmarried girl had DIE with bilateral endometriosis with haematosalpinx. Endometriosis is found in $45 \%-82 \%$ of women with chronic pelvic pain. ${ }^{10}$ Chronic pelvic pain and dysmenorrhea were presenting complaints in all the cases in our study, with majority of them having palpable abdominopelvic mass. CA-125 was marginally raised in all cases in our study. Evidence also suggests slight increase in levels of CA125.11 However, it is not recommended to confirm the diagnosis of endometriosis.

Detailed history taking regarding the patient's menstrual, reproductive and sexual health can reveal signs and symptoms of endometriosis helping in early diagnosis, further corroborated by physical examination. Ultrasonography, MRI (method of choice for DIE), IVP (for ureteric involvement), cystoscopy and rectosigmoidoscopy are informative in knowing the extent of disease. ${ }^{12}$ Presence of $\mathrm{T}_{1}$ weighted hyperintensity within a dilated fallopian tube is suggestive of endometriosis and may be the only finding at MR imaging in some women, ${ }^{13}$ as observed in majority of our cases. The quality of life can be improved in a case with by medical methods like NSAIDs, oral contraceptive pills, progesterones (oral, injectable and intrauterine devices), SPRMs (Selective Progesterone Receptor Modulators), Gonadotropin releasing hormone Agonists. Research is also underway for nonhormonal therapy involving VEGF antagonists, immunoconjugates and stem cells. ${ }^{14}$

Need of surgery depends upon the size of endometrioma, enhancement of fertility, better pain relief or failure of medical management. Surgery with conservative resection of large endometriomas greater than $5 \mathrm{cms}$ and pelvic adhesiolysis followed by long term medical treatment is recommended in adolescents. Operative laparoscopy is superior to laparotomy in management of DIE, however it may depend on surgeon's expertise and experience. Microsurgical techniques with careful and precise dissection should be practised to cause minimal trauma, tissue ischaemia, inflammation and adhesion formation ${ }^{15}$. Women with infertility and DIE and endometrioma of more than $5 \mathrm{cms}$ should proceed for conservative surgical resection of implants followed by IVF as these women with advanced disease have decreased ovarian reserve, poor oocyte and poor embryo quality with poor implantation ${ }^{16}$. Prolonged GnRH agonists given prior to IVF, improves results in cases with stage 4 endometriosis 17 . Medical management may be continued after the surgery. After childbearing age total abdominal hysterectomy with bilateral salpingo-oophorectomy remains the treatment of choice.

\section{CONCLUSIONS}

Diagnosis of endometriosis should always be kept a possibility in all age groups, from adolescence till menopause. Chronic pelvic pain, congestive dysmenorrhea, palpable abdominopelvic mass and infertility remain diagnostic presenting symptoms. Also, possibility of an endometrioma in a perimenopausal patient presenting with an adnexal mass should be kept in mind. Serum CA-125 levels are marginally raised in majority of cases with stage 3 and 4 DIE endometriosis. Conservative surgical resection followed by long-term medical treatment in adolescents remains the choice. In DIE associated with infertility, resection of endometriosis followed by GnRH agonists and IVF should be recommended. All perimenopausal women with severe endometriosis, total abdominal hysterectomy with bilateral salpingo-oophorectomy is standard management.

\section{REFERENCES}

[1] Leibson CL, Good AE, Hass SL, et al. Incidence and characterization of diagnosed endometriosis in a 
geographically defined population. Fertility and Sterility 2004;82(2):314-21.

[2] Halis G, Mechsner S, Ebert AD. The diagnosis and treatment of deep infiltrating endometriosis. Deutsches Aerzteblatt Online 2010;107(25):446-56.

[3] Lo Momnte G, Wenger JM, Petignat $P$, et al. Role of imaging in endometriosis. Cleveland Clinic Journal of Medicine 2014;81(6):361-6.

[4] Peterson CM, Johnstone EB, Hammoud AO, et al. Risk factors associated with endometriosis: importance of study population for characterizing disease in the ENDO Study. American Journal of Obstetrics and Gynecology 2013;208(6):451.e1-e11.

[5] Chapron C, Fauconnier A, Dubuisson JB, et al. Deep infiltrating endometriosis: relation between severity of dysmenorrhoea and extent of disease. Human Reproduction 2003;18(4):760-6.

[6] Parmjit K, Bhatia R, Dev A, et al. Bilateral endometriomas with deep infiltrating endometriosis in infertility: an increasing trend. Asian Journal of Obstetrics and Gynaecology Practice 2017;1(4):16-20.

[7] Kaur P, Bhatia R, Singh KD, et al. Bilateral fetal head size endometriomas with deep infiltrating endometriosis in an adolescent girl. Med Res Chron 2015;2(3):425-9.

[8] Brosens I, Puttemans P, Benagiano G. Endometriosis: a life cycle approach. American Journal of Obstetrics and Gynecology 2013;209(4):307-16.
[9] Rock JA, Howard WH. Te Linde's Operative Gynaecology. Endometriosis. Lippincott Williams \& Wilkins 2009;22:438-73.

[10] Mishra VV, Gaddagi RA, Aggarwal R, et al. Prevalence, characteristics and management of endometriosis amongst infertile women: a one year retrospective study. J Clin Diagn Res 2015;9(6):QC01-QC03.

[11] Kitawaki J, Ishihara $H$, Koshiba $H$, et al. Usefulness and limits of CA-125 in diagnosis of endometriosis without associated ovarian endometriomas. Human Reproduction 2005;20(7):1999-2003.

[12] Hsu AL, Khachikyan I, Stratton P. Invasive and noninvasive methods for the diagnosis of endometriosis. Clinical Obstetrics and Gynecology 2010;53(2):413-9.

[13] Outwater EK, Siegelman ES, Chiowanich P, et al. Dilated fallopian tubes: MR imaging characteristics. Radiology 1998;208(2):463-9.

[14] Attar R, Attar E. Experimental treatments of endometriosis. Womens Health (Lond) 2015;11(5):65364.

[15] Kondo W, Bourdel N, Zomer MT, et al. Surgery for deep infiltrating endometriosis: technique and rationale. Frontiers in Bioscience 2013;5(1):316-32.

[16] Sanchez AM, Vanni VS, Bartiromo L, et al. Is the oocyte quality affected by endometriosis? A review of the literature. Journal of Ovarian Research 2017;10(1):43.

[17] Surrey ES. Endometriosis related infertility: the role of the assisted reproductive technologies. Article ID 482959, BioMed Research International 2015;2015:1-8. 